Brit. Heart J., 1965, 27, 791.

\title{
LIVER FUNCTION IN PULMONARY HEART DISEASE
}

\author{
BY \\ ARTHUR J. THOMAS, HARRY A. REES, AND R. A. SAUNDERS \\ From Llandough Hospital (United Cardiff Hospitals), Penarth, Glamorgan
}

Received January 1, 1965

It is well recognized that some liver function tests are abnormal in heart failure (Jolliffe, 1930; Felder, Mund, and Parker, 1950; Sherlock, 1951; White et al., 1955; Cantarow and Trumper, 1962). Richman, Delman, and Grob (1961) described alterations in indices of liver function in congestive heart failure with particular reference to serum enzymes and drew attention to the increased frequency of abnormal patterns of the tests in episodes of acute heart failure as against chronic heart failure. They and others have found the alkaline phosphatase, thymol turbidity, thymol flocculation, serum proteins, bilirubin, and cholesterol levels relatively insensitive in chronic heart failure (Felder et al., 1950). Richman et al. found the SGOT increased in 33 per cent of patients with increases limited almost entirely to those with acute failure. El-Shaboury, Thomas, and Williams (1964) found increases in SGOT levels in many patients with acute exacerbation of asthma, but without evidence of heart failure. Refsum (1963) showed a close correlation between SGOT and SGPT levels and severity of arterial hypoxæmia in severe pulmonary insufficiency. He remarked on the lack of correlation between the enzymatic changes and clinical signs of right heart failure.

In most work the bromsulphthalein (BSP) retention was the most sensitive index of hepatic disorder in heart failure (Sherlock, 1951; Richman et al., 1961; Cantarow and Trumper, 1962). Maclagan and Rundle (1940) described the place of the galactose tolerance test in thyrotoxicosis and suggested that when the galactose index was high structural liver damage was present. It has been suggested that more rapid and complete intestinal absorption of galactose may play a part in this test in thyrotoxicosis, but apart from this, the galactose tolerance test is a test of structural liver damage (Cantarow and Trumper, 1962). The galactose may be given orally or intravenously and the measurements made either in the blood over a period of time up to two hours or in urine collected for five hours. Long experience of the oral galactose test with estimations made on blood samples as described by Maclagan and Rundle (1940) has satisfied us of its reliability and value.

The present investigation was undertaken because of the observation that necropsy of the liver in many cases of pulmonary heart disease showed chronic passive venous congestion when right heart failure had not been noted during life. The galactose tolerance test was particularly studied but other indices of liver function were also recorded.

\section{Method AND Subjects}

At 9 a.m., after an overnight fast, 40 g. of galactose in solution was given orally. The blood sugar was estimated on blood taken just before the galactose was given and at half-hourly intervals for 2 hours afterwards. The majority of blood samples were taken by finger-prick method, but specimens for duplicate testing and comparison of methods were venous blood samples preserved with fluoride-oxalate.

The blood sugar was estimated using the Haslewood and Strookman method which is practically specific for true sugars. In 6 cases, parallel tests were carried out using the above method and using a glucoseoxidase method for estimating blood glucose. The results of the glucose-oxidase method showed that the 
fasting sugar as estimated above was glucose and that during the test the glucose level altered little, making no appreciable difference to the calculated index. The galactose index (GI) is the sum in $\mathrm{mg} . / 100 \mathrm{ml}$. of the increases in the four specimens over the fasting level.

In 6 cases the intravenous test was used and the finding of $30 \mathrm{mg} . / 100 \mathrm{ml}$. or more of galactose in the blood after 45 minutes agreed well with a galactose index of 140 or over when the test was repeated in this way some days later.

The BSP retention, serum enzyme estimations, and standard liver function tests were done. Lung function tests, including the forced expiratory volume in one second $\left(\mathrm{FEV}_{1}\right)$ and forced vital capacity or the peak flow rate, were recorded. In 27 cases the $\mathrm{PcO}_{2}$ was measured by the Astrup method and in 20 the $\mathrm{SaO}_{2}$ was measured on a Brinkmann Hæmoreflector.

Forty-eight measurements of the GI were made in 41 patients with moderate to severe pulmonary disease. All the patients had severe obstructive airways disease with $\mathrm{FEV}_{1}$ ranging from 0.41 . to 1.31 . when the predicted $\mathrm{FEV}_{1}$, as calculated from the formula suggested by Kory et al. (1961), ranged from $2 \cdot 11$. to 3.8 1. Clinically, all had chronic bronchitis, and 8 of these had pneumoconiosis of some degree; 6 other patients had a slight or moderate degree of bronchiectasis and chronic bronchitis. Of the 41,10 had been in clinical heart failure shortly before the test was done or were still in heart failure at the time of the test; 27 had evidence of pulmonary heart disease on the cardiogram, using the cardiographic criteria of pulmonary heart disease listed by Rees, Thomas, and Rossiter (1964).

\section{RESULTS}

The results in 13 normal subjects are shown in Fig. 1. In our series the mean normal figure for the GI was 74 units (range 10-130). In 15 patients with heart disease with no question of heart failure at any time the mean was 84 units (range 30-137). In 8 patients with non-toxic thyroid disorder the mean reading was 79 units (range 9-113). In 26 patients with thyrotoxicosis the mean reading was 242 units (range 140-755). In 10 patients with moderate heart failure of non-pulmonary origin the mean reading was 211 units (range 129-387), and only two readings were below 140 units. Thus on the basis of the findings in these 71 non-pulmonary patients supported by previous experience of the test in doubtful cases of thyrotoxicosis, we considered the test a reliable index of liver dysfunction and a GI of 140 units or above as indicating abnormality.

Of the 48 readings in pulmonary disease, 39 were at or above 140 units (Fig. 1). There was a fair scatter in relation to the $\mathrm{FEV}_{1}$, but the trend of the scatter was entirely towards increase above 140

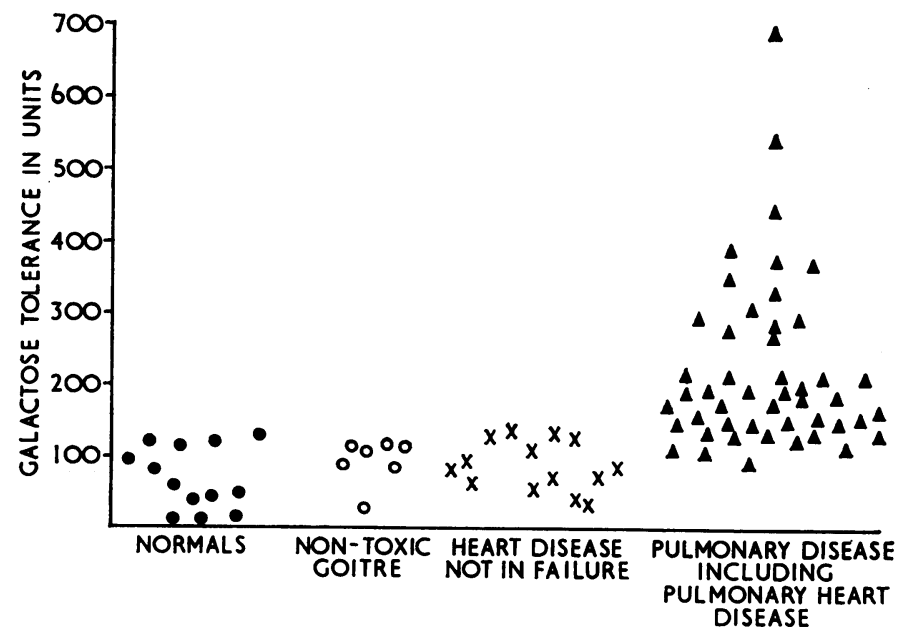

FIG. 1.-The galactose tolerance expressed as an index (GI) in patients with pulmonary disease is compared with the GI in normal subjects, non-toxic goitre subjects, and heart disease patients
not in failure. 


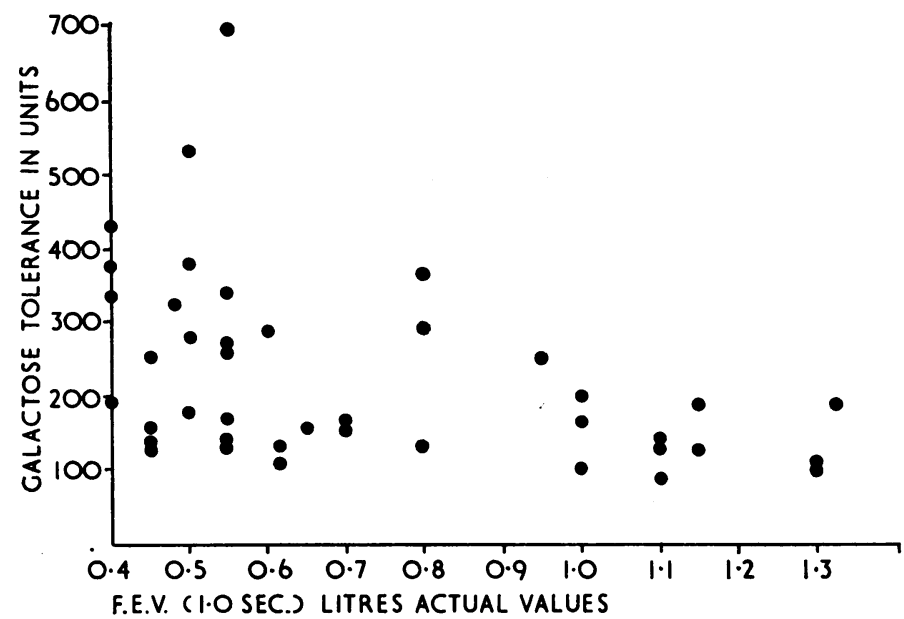

FIG. 2.-The distribution of the GI in relation to the $\mathrm{FEV}_{1}$ shows that the more severe the obstructive airways disease the higher the GI.

units with reduction in $\mathrm{FEV}_{1}$ (Fig. 2). The change was not related only to the ventilatory reduction, as indicated by the scatter at the low $\mathrm{FEV}_{1}$ readings, for example as seen at $\mathrm{FEV}_{1} 0.51$. to 0.61 .

In Fig. 3 the GI is compared with a number of other indices. In 21 of the 28 patients a BSP retention was measured, and this agreed reasonably well with the GI, but there were 6 patients in whom the GI was raised when the BSP retention was normal and 3 with GI below 140 units and

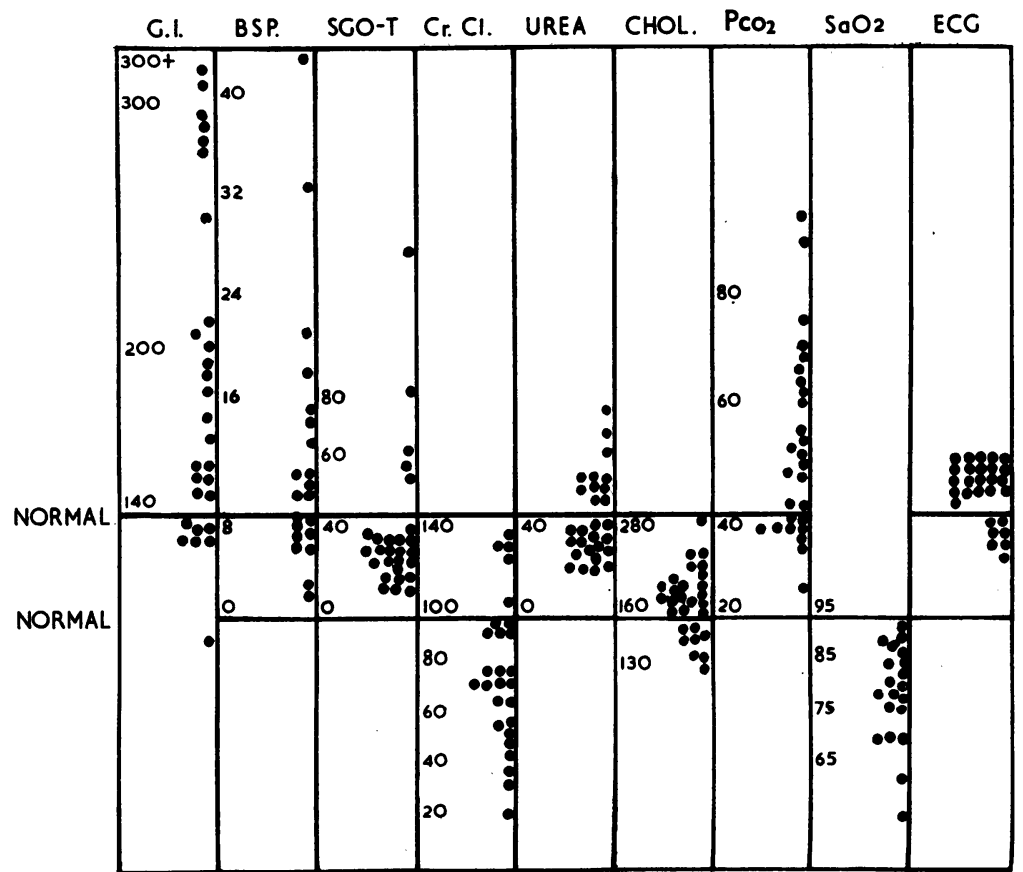

FIG. 3.-The GI is compared with a number of other indices (discussed in the text). $\mathrm{Cr}$. $\mathrm{Cl}$., creatinine clearance in $\mathrm{ml} . / \mathrm{min}$. Chol., serum cholesterol. ECG, marks above the normal line indicate pulmonary heart disease. 
TABLE

Galactose Index in Patients in and out of Heart Failure

\begin{tabular}{|c|c|c|c|c|c|c|}
\hline \multirow{3}{*}{ Case No. } & \multicolumn{3}{|c|}{ Heart failure } & \multicolumn{3}{|c|}{ No heart failure } \\
\hline & \multirow{2}{*}{ GI } & \multicolumn{2}{|c|}{ BSP $\%$ retention } & \multirow{2}{*}{ GI } & \multicolumn{2}{|c|}{ BSP $\%$ retention } \\
\hline & & $20 \mathrm{~min}$. & $45 \mathrm{~min}$. & & $20 \mathrm{~min}$. & $45 \mathrm{~min}$. \\
\hline $\begin{array}{l}1 \\
2^{*} \\
3^{*} \\
4 \\
5 \\
6\end{array}$ & $\begin{array}{l}178 \\
219 \\
289 \\
282 \\
211 \\
539\end{array}$ & $\begin{array}{l}35 \\
30 \cdot 5 \\
-\overline{26} \\
15 \\
6\end{array}$ & $\begin{array}{l}26 \\
18 \\
46 \\
15 \cdot 7 \\
5 \\
4 \cdot 5\end{array}$ & $\begin{array}{r}30 \\
284 \\
692 \\
345 \\
146 \\
283\end{array}$ & $\begin{array}{c}26 \\
28 \\
55 \\
38 \\
6 \cdot 2 \\
21\end{array}$ & $\begin{array}{c}19 \\
22 \\
19 \\
7 \cdot 5 \\
1 \cdot 3 \\
10 \cdot 5\end{array}$ \\
\hline
\end{tabular}

* Died shortly afterwards.

Note: Cases 2, 3, and 4 had lost their œdema but still had severe respiratory insufficiency.

increased BSP retention. The difference was further emphasized in 3 patients by repeat GI measurements in and out of heart failure. In one who was improving from failure the BSP retention was higher when the GI fell, and in one, whose condition worsened and who subsequently died, the GI moved from 282 to 692 , but the BSP retention fell from 46 to 19 per cent (Table). The two tests followed the same trend in most patients but there were occasional exceptions and the GI followed the clinical condition rather better than the BSP retention.

The other test which agrees well with the GI is the $\mathrm{PcO}_{2}$ as measured in 27 of the 28 patients, those with high GI being those with high $\mathrm{Pco}_{2}$ levels. These patients are of course those with the lowered $\mathrm{SaO}_{2}$ and where they were measured the agreement was good. The SGOT of patients with chronic bronchitis and pneumoconiosis is often normal. In only 5 patients was the SGOT raised and these had become hypoxic rather quickly. This supports the impression from other work that the SGOT is likely to be normal in chronic pulmonary heart failure, and is more likely to be abnormal in episodes of either very acute failure or of acute hypoxia. The results of creatine clearance and blood urea level are indicated in Fig. 3, and the creatinine clearance was reduced in 22 out of 27 patients. This is a frequent finding in severe pulmonary disease and in pulmonary heart failure. The creatinine clearance tends to improve fairly rapidly with clinical improvement in the patient. In this series the creatinine clearances showed no correlation with the GI and the reduced clearance could not account for the increased GI.

The Table shows the comparison in 6 patients studied in detail when in and out of clinical heart failure, but when still ill with respiratory insufficiency. These measurements were made within weeks of each other. In 3 of them the patient was improving and coming out of heart failure and the GI reflects this improvement. In 2, the patient was worsening and subsequently died and the GI showed considerable increase as the condition worsened. Altogether 12 patients in this series have died, but necropsy studies were carried out in only 6 . All 6 had a high GI and all 6 had a high degree of chronic venous congestion with centrilobular necrosis in the liver and the one with the highest GI had evidence of severe hepatic necrosis.

\section{Discussion}

In some studies on the liver in heart failure reference is made to patients with pulmonary heart disease where there is considerable change in liver function. Sherlock (1951) refers to 9 patients with pulmonary heart failure, 5 of whom had liver changes; Richman et al. (1961) have 10 with pulmonary heart disease, and White et al. (1955) give 2 with similar changes. These are cases of clinical right heart failure. Such heart failure can undoubtedly produce centrilobular hepatic necrosis, and in 5 such subjects with pulmonary heart failure the reduced arterial oxygen saturation 
seemed an important factor in the production of the liver lesion. There was also a good correlation with increased right atrial pressure (Sherlock, 1951).

Post-mortem study of the liver in heart failure or hypoxia is known to be unreliable, but the changes seen in pulmonary heart disease seemed to us out of proportion to the clinical failure. One of us (Thomas, 1948) noted that a palpable tender liver margin with anorexia and weight loss was a warning of impending pulmonary heart failure. The routine clinical tests of liver function did not emphasize this until either the bromsulphthalein or the galactose tolerance test or both were done. We agree with Richman et al. that the SGOT and SGPT are more likely to be increased in acute heart failure, and our experience in asthma (El-Shaboury et al., 1964) suggests that this may include acute hypoxia even without clinical heart failure. Refsum (1963) also shows that hypoxæmia can lead to severe liver cell destruction.

In chronic pulmonary heart disease, defined by Woild Health Organization (1961) and recognized clinically and cardiographically, there need not be signs of right heart failure. Yet there is evidence of liver damage which is best shown by the galactose tolerance and bromsulphthalein tests. Improvement in the patient is reflected in improvement in the tests. In 2 patients improvement in "heart failure," i.e. a lessening of œdema and a drop in jugular venous pressure, without any corresponding improvement in respiratory function or hypoxia, was accompanied by an increase in the GI. In a group of patients the increasing GI index broadly follows the diminishing ventilatory capacity as shown by the $\mathrm{FEV}_{1}$ and the FVC. It also follows the increase in $\mathrm{Pco}_{2}$ and the decrease in $\mathrm{SaO}_{2}$. In another series (Thomas, Cotes, and Pisa, 1963) the diminished ventilatory function, raised $\mathrm{Pco}_{2}$, and diminished $\mathrm{SaO}_{2}$ correlated well with the pulmonary arterial mean pressure.

The evidence in the present study points to detectable liver damage being present in most cases of severe obstructive airways disease, even before there is evidence of pulmonary heart disease. This liver damage is reversible. Most of the patients in this series with severe airways obstruction $\left(\mathrm{FEV}_{1}\right.$ persistently $<1 \cdot 21$.) and the majority of those with cardiographic signs of pulmonary heart disease gave evidence of liver damage as assessed by the galactose tolerance test. This liver change was related to the degree of airways obstruction, to the degree of hypoxia, and by inference to the increase in pulmonary arterial mean pressure. It seems from this work that hepatic congestion must be present or hypoxic liver damage must exist before clinical cardiac failure is recognized in severe obstructive airways disease. Pulmonary heart disease is recognized before cardiac failure occurs and the galactose tolerance test may well be a helpful addition to its study. The principal pulmonary disorder in this series was "chronic bronchitis", and the galactose tolerance test may well help in assessing the severity of this condition.

\section{SUMMARY}

The liver function in severe pulmonary disease (obstructive airways disease) has been studied by means of the galactose tolerance test. Expressing the results as an "index", 39 of 48 readings are 140 units or above, and this is considered an indication of disturbed liver function due to the pulmonary disease. There is a trend towards increase in the galactose index with reduction in ventilatory function as expressed by the $\mathrm{FEV}_{1}$. This index and the bromsulphthalein retention compare well. It is interesting that increase in the galactose index and so disordered liver function is evident in pulmonary heart disease before clinical cardiac failure is present, suggesting either that hypoxia may be a factor in causing the disordered liver function, or that hepatic congestion is present in advance of other signs of clinical cardiac failure.

We are indebted to Dr. T. Parry, Consultant Pathologist to Llandough Hospital, and Dr. D. M. D. Evans, Consultant Pathologist to St. David's Hospital, for the laboratory facilities. We acknowledge with gratitude financial support for the study of pulmonary heart disease from the Endowment Fund of the United Cardiff Hospitals and from the British Heart Foundation. 


\section{REFERENCES}

Cantarow, A., and Trumper, M. (1962). Clinical Biochemistry, 6th ed., p. 545. W. B. Saunders, London.

El-Shaboury, A. H., Thomas, A. J., and Williams, D. A. (1964). Serum transaminase activity in status asthmaticus. Brit. med. J., 1, 1220.

Felder, L., Mund, A., and Parker, J. G. (1950). Liver function tests in chronic congestive heart failure. Circulation, 2, 286.

Jolliffe, N. (1930). Liver function in congestive heart failure. J. clin. Invest., 8, 419.

Kory, R. C., Callahan, R., Boren, H. G., and Syner, J. C. (1961). The Veterans Administration-Army cooperative study of pulmonary function. I. Clinical spirometry in normal men. Amer. J. Med., 30, 243.

Maclagan, N. F., and Rundle, F. F. (1940). Liver function in thyrotoxicosis. Quart. J. Med., 9, 215.

Rees, H. A., Thomas, A. J., and Rossiter, C. (1964). The recognition of coronary heart disease in the presence of pulmonary disease. Brit. Heart J., 26, 233.

Refsum, H. E. (1963). Arterial hypoxæmia, serum activities of GO-T, GP-T, and LDH., and centrilobular liver cell necrosis in pulmonary insufficiency. Clin. Sci., 25, 369.

Richman, S. M., Delman, A. J., and Grob, D. (1961). Alterations in indices of liver function in congestive heart failure with particular reference to serum enzymes. Amer. J. Med., 30, 211.

Sherlock, S. (1951). The liver in heart failure: Relation of anatomical, functional, and circulatory changes. Brit. Heart J., 13, 273.

Thomas, A. J. (1948). The heart in pneumoconiosis of coalminers. Brit. Heart J., 10, 282.

$\longrightarrow$, Cotes, J. E., and Pisa, Z. (1963). Pulmonary hypertension in patients with chronic lung disease. Proc. IV World Cong. Cardiol., Mexico, 1B, 180.

White, T. J., Leevy, C. M., Brusca, A. M., and Gnassi, A. M. (1955). The liver in congestive heart failure. Amer. Heart J., 49, 250.

World Health Organization (1961). Chronic cor pulmonale. Wld Hlth Org. techn. Rep. Ser., No. 213. 